\title{
EFFECTS OF BARIATRIC SURGERY ON BLOOD PRESSURE OF NON-HYPERTENSIVE OBESE PATIENTS
}

João Sérgio Neves ${ }^{1}$, Sofia Castro Oliveira ${ }^{1,2}$, Pedro Souteiro ${ }^{1,2}$, Rita Bettencourt-Silva ${ }^{1,2}$, Daniela Magalhães ${ }^{1,2}$, Maria Manuel Costa ${ }^{1,2}$, Ana Saavedra ${ }^{1,2}$, Joana Oliveira ${ }^{1,2}$, Filipe Cunha ${ }^{1,2}$, Eva Lau ${ }^{1,2}$, César Esteves ${ }^{1,2}$, Sandra Belo ${ }^{1,2}$, Ana Cristina Santos ${ }^{4}$, Paula Freitas ${ }^{1,2,3}$, Joana Queirós ${ }^{1,3}$, Ana Varela ${ }^{1,3}$, Flora Correia ${ }^{3,5}$, Davide Carvalho ${ }^{1,2}$ \& Grupo AMTCO ${ }^{3}$

${ }^{1}$ Department of Endocrinology, Diabetes and Metabolism, São João Hospital Center, Faculty of Medicine of the University of Porto, Porto, Portugal; ${ }^{2}$ Instituto de Investigação e Inovação em Saúde, University of Porto, Porto, Portugal; ${ }^{3}$ Multidisciplinary Group for Surgical Treatment of Obesity, São João Hospital Center, Porto, Portugal; ${ }^{4}$ Clinical Epidemiology, Predictive Medicine and Public Health Department of FMUP, Porto, Portugal; ${ }^{5}$ Faculty of Nutrition and Food Sciences of University of Porto, Porto, Portugal.

\section{INTRODUCTION}

Increased blood pressure (BP) above $>\mathbf{1 1 5} / \mathbf{7 5} \mathbf{m m H g}$ presents an independent association with cardiovascular events. Although there is a clear benefit of bariatric surgery on BP of hypertensive patients, the impact in non-hypertensive patients remains largely unknown. Therefore, the aim of our work was to evaluate the impact of bariatric surgery on BP of non-hypertensive obese patients.

\section{Methods ANd Results}

\section{Methods}

- We evaluated a cohort of 224 non-hypertensive obese patients that were submitted to bariatric surgery.

- We evaluated the variation of systolic BP (SBP) and diastolic BP (DBP) 12 months after surgery.

- The statistical analysis was done with Student's t-Test, Pearson correlation and Multiple regression.

- A P value of $<0.05$ was considered statistically significant.
- We evaluated the impact of:

-Age
-Gender
-Body mass index (BMI)
-Waist-to-hip ratio
-Systolic BP (SBP)
- Diastolic BP (DBP)
-Diabetes

- Dyslipidemia

- Smoking

- C-Reactive Protein

- Glomerular Filtration Rate (GFR)

- Type of surgery (gastric band, gastric bypass or sleeve gastrectomy)

- Weight loss after surgery (12 months)

\section{RESULTS}

Table 1. Population characteristics

\begin{tabular}{|lc|}
\hline Age, years & $41.8 \pm 9.3$ \\
\hline Gender & \\
\hline Men, $\%$ & $9.2 \%$ \\
\hline Women, \% & $90.8 \%$ \\
\hline Type of surgery & \\
\hline Gastric band & $21.9 \%$ \\
\hline Gastric bypass & $65.6 \%$ \\
\hline Sleeve gastrectomy & $12.5 \%$ \\
\hline BMI, kg/m² & $43.5 \pm 4.6$ \\
\hline Waist-to-hip ratio & $0.92 \pm 0.81$ \\
\hline SBP, mmHg & $122.4 \pm 10.9$ \\
\hline DBP, mmHg & $77.4 \pm 8.4$ \\
\hline Diabetes, \% & $11.3 \%$ \\
\hline Smoking, \% & $14.2 \%$ \\
\hline GFR, mL/min/1,73m2 & $95.7 \pm 24.1$ \\
\hline Weight loss at 12m, kg & $33.9 \pm 13.0$ \\
\hline
\end{tabular}

Table 2. Models of Multiple Linear Regression

\begin{tabular}{|lccc|}
\hline & Coefficient $(\boldsymbol{\beta})$ & Standard Error & $\boldsymbol{P}$ \\
\hline SBP Reduction & & & \\
\hline Initial SBP, $\mathrm{mmHg}$ & 0,202 & 0,107 & $<0,001$ \\
\hline Initial DBP, $\mathrm{mmHg}$ & $-0,331$ & 0,136 & 0,015 \\
\hline Weight loss, $\mathrm{kg}$ & 0,975 & 0,098 & $<0,001$ \\
\hline Age, years & $-0,249$ & 0,114 & 0,030 \\
\hline Initial BMI, $\mathrm{kg} / \mathrm{m}^{2}$ & $-0,549$ & 0,252 & 0,030 \\
\hline DBP Reduction & & & \\
\hline Initial DBP, $\mathrm{mmHg}$ & 0,769 & 0,070 & $<0,001$ \\
\hline Age, years & $-0,135$ & 0,067 & 0,044 \\
\hline Initial BMI, $\mathrm{kg} / \mathrm{m}^{2}$ & $-0,335$ & 0,144 & 0,021 \\
\hline & The other variables evaluated did not present statistically significant effects \\
\hline
\end{tabular}

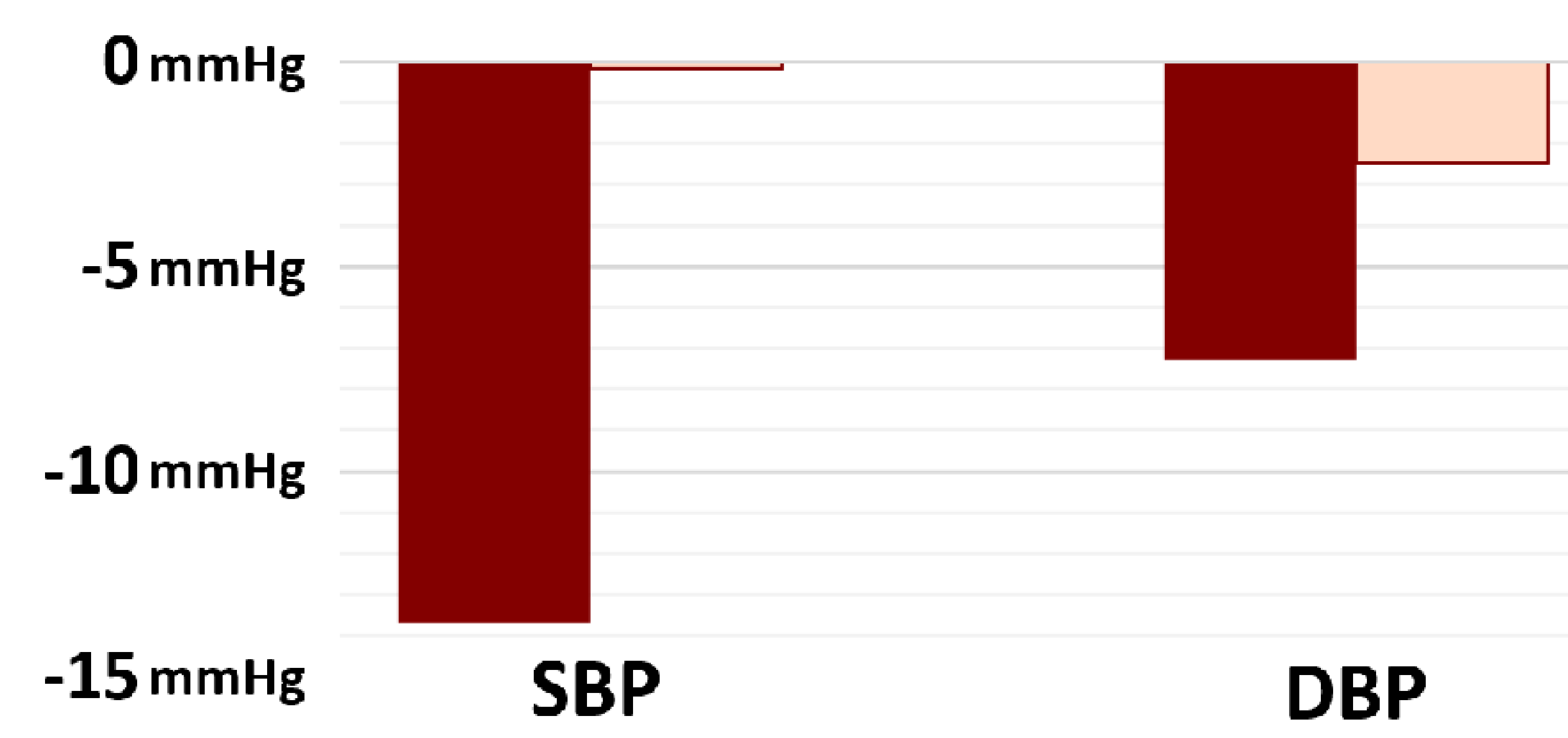

$130-140 \mathrm{mmHg}$

$<130 \mathrm{mmHg}$

Graphic 1. SBP and DBP reduction by subgroups of initial SBP

\section{Conclusions}

Bariatric surgery contributes to a significant reduction of BP in non-hypertensive obese patients. The benefit appears to be more directly related to weight loss than to type of surgery. The impact of the procedure is greater in patients with higher initial SBP, and smaller in older patients and those with higher BMI. 